\title{
12 Sources of asymmetry in human interaction: enchrony, status, knowledge and agency
}

\section{N.J. Enfield}

As conversation analysis forges new directions, it also faces significant challenges in a world of developing research, and shifting research interests. My purpose in this chapter is to address one of these challenges: to define more explicitly the elements of a framework that will license and constrain the observed structures of social interaction, and in turn their proper analysis. Part of the goal is to offer an account of human interaction that is general enough to address broader, interdisciplinary questions of the study of human behavior.

I aim to explicate a theoretical foundation for understanding the kinds of phenomena dealt with in the above chapters - that is, the negotiation of knowledge, responsibility and affiliation in interaction - building on four related concepts: enchrony, status, knowledge and agency. Each builds from the next, where enchrony entails accountability, status relativizes it, knowledge grounds it, and agency distributes it. Each is a source of asymmetry, and each thereby plays a role in defining a possibility space in the morality of knowledge in communication. The four concepts are well established in existing literature, although they may be known by other names, and may not have been brought together in quite the same way as here.

\section{Enchrony}

Our first element is a primal driving force for the ever-forward progression of social interaction, a force from which we derive sequence (Schegloff 2007b), from its simplest to its most complex manifestations.

With admiration for true primary authority on the topic at hand. this chapter is dedicated to Paul Drew or John Heritage. Very many thanks to Tanya Stivers for urging me to write this chapter, for extensive discussion of the contents, and for supplying me with data. Any errors of fact or interpretation are entirely due to her. For comments on earlier versions of the text, I thank John Heritage. Kobin Kendrick, Lorenza Mondada. Lila San Roque. Jack Sidnell and Tanya Stivers. I also thank participants at a presentation of these ideas at MPI Nijmegen in Spring 2009 for their feedback. This work was carried out within the Multimodal Interaction Project in the Language and Cognition Group at the Max Planck Institute for Psycholinguistics, and was funded by the Max Planck Society and the European Research Council. 
Because human interaction is a form of animal communication, we may start with the simple observation that communicative interaction involves formally ritualized patterns of behavior, which bring about relatively predictable effects on others in the social realm (Krebs and Dawkins 1984). This conception of social interaction entails a dynamic relation between a communicative action and the response it elicits. And, in turn, such a reaction may in itself be a communicative action, engendering, in response, a further communicative action (see below). Moreover, any sequence "communicative action and subsequent response" is a unit, not a conjunct. The sequence cannot be derived from independently established concepts "communicative action" and "response." This is because neither may be defined without the other. The relation between communicative action and response is critical to defining them both. We may speak of a communicative action in isolation only if we bracket out the notion of response (and vice versa), because in fact a communicative action can only be known to be a communicative action insofar as it is known to elicit a relatively predictable or motivated response. ${ }^{1}$

"Response" here is not the highly constrained notion captured by "answer" (e.g., to a question). It has a more general sense, i.e., that which follows and is occasioned by, and relevant to, something prior. Consider the $B$ lines in the following service encounters (examples from Merritt [1976: 325,333 and 331 , respectively]):

(1)

A: Do you have coffee to go?

B: Cream and sugar? starts to pour coffee

A: What'll ya have girls?

B: What's the soup of the day?

A: Do you sell key chains?

B: What?

The B turns do not directly address the ostensive content of the questions that precede them, though each is a response in the sense intended here. In different ways, each is directly relevant to, and occasioned by, what came just before it.

1 Human communicative actions do not merely cause their responses to occur as heat causes ice to melt. This is because responses are oriented not only to the perceptible signs out of which communicative actions are formed, but also to what those communicative actions mean or "stand for" (Kockelman 2005; Peirce 1955). A response to some physical event like an action is what Peirce called an interpretant. An interpretant makes sense in terms of the sign's object, i.e., what the sign stands for. 
Once our concept of communication incorporates this fundamental dynamic semiotic process $-\operatorname{sign}^{2}$ and response - notice what results when we see that the response is typically also a communicative action itself. Each communicative action simultaneously occupies a backward-looking status as "that which responds to what just happened" and a forwardlooking status as "that which elicits a response next." Responses to communicative actions are new communicative actions, and they engender new responses, in turn. I refer to the local relation between a sign and its response as relevance (cf. Sperber and Wilson 1995). Because a response may be a sign in itself, which may beget a new response, we can derive a potentially unbounded sequence of such pivoting sign-response relations. I refer to this forward-feeding temporal, causal-conditional trajectory of relevance relations as enchrony (Enfield 2009: 10).

Why introduce a new term if we already have adequate analytic concepts and terms such as sequence, adjacency, nextness, contiguity and progressivity (Schegloff 2007b:14)? A first reason is that each of these existing terms denotes something narrower than what I want to denote by the term "enchrony." Enchrony does not replace those terms or concepts. It refers to a more general force that underlies their emergence. A second reason for the term is to draw attention to this family of notions under a single rubric, and to place the rubric within a broader, interdisciplinary set of alternative perspectives for the analysis of human communication. An enchronic perspective on human communication focuses on sequences of interlocking or interdependent communicative moves that are taken to be co-relevant, and causally-conditionally related. Enchrony is a level of temporal-causal grain (typically, "conversational time") that an analyst of communication can adopt, as distinct from other possible perspectives, fitted to other purposes, that focus on other temporal scales and other kinds of causal-conditional process; these include phylogenetic, diachronic, ontogenetic, epigenetic and synchronic perspectives.

An enchronic perspective is grounded in trajectories of co-relevant actions, a phenomenon observed by scholars of social action from Schütz

2 For convenience, I shall sometimes use the word "sign" to refer to a communicative action, though the terms "sign" and "action" are not synonymous. While all communicative actions are built out of signs. not all signs are communicative actions. Like other students of social interaction, I am interested in how communicative actions can be recognized by those who perceive them, and in turn how these actions should therefore be formulated (by those who produce them) in order to secure this recognition. The only kind of theory that can account for how social actions are recognized is a semiotic theory (e.g., Kockelman 2005,2006 b) - that is, a theory that defines the means by which people can use perceptions of their environment as cues for making inferences to what is not directly observable (e.g.. others" apparent motivations and goals). 
and Mead to Goffman and Garfinkel, to Sacks, Schegloff and Jefferson, to Heritage, Drew and many others since. A communicative action or move (Goffman 1981) has what Schütz (1970) referred to as "because motives" (what gave rise to the move, what occasioned it) and "in-order-to motives" (the goals of the move, what it hopes to bring about): I'm pouring a drink because I'm thirsty, and in order to drink it. The move is a step in a sequence of events where each such step interlocks relevantly and coherently both with something that just happened (or that otherwise already applied in the context of the move) and with something that happens next. This Peircean conception of meaning as inherently dynamic is distinctly unlike the static Saussurean version (Enfield 2009; Kockelman 2005), and it is the one that is best understood by analysts of tape-recorded sequences of human interaction since the likes of Sacks (e.g., 1992: I, 3-11) and Schegloff (e.g., 1968).

Communicative actions in enchronic sequences are hooked together in a special way. They do not randomly follow one another. As both analysts and participants, we incorrigibly take enchrony to be operative, and we go to great lengths to interpret actions as connected by relevance, even when there is no such relation. As Garfinkel advises, people will always understand your actions, just not always in the way you intended. A vivid demonstration comes from a 1960s experiment conducted in the Department of Psychiatry at UCLA (Garfinkel 1967: ch. 3). Subjects were asked to take part in a new form of therapy where they would pose their problems as a series of questions, to which the counselor's answers could only be "yes" or "no." Unbeknownst to subjects, the series of "yes" and "no" responses that they received from their unseen "counselor" were randomly predetermined. Whether an answer was "yes" or "no" had no relation to the question being posed. Yet all the subjects perceived the responses "as answers to their questions" (Garfinkel 1967: 89). I cannot do justice here to Garfinkel's rich discussion of the findings regarding this notion of an incorrigible projection of relevance (see his pp. 89-94), but I simply note here the tremendous strength of an enchronic stance adopted in everyday life. It shows up, for instance, in globally attested practices of divination, in which essentially random events - such as whether a ritual spider walks to the left or to the right when released from its lair - are interpreted as properly responsive to questions posed (Goody 1995; Lévi-Strauss 1966; Zeitlyn 1995).

This glue or hook between adjacent moves can be characterized as a pair of arrows, one pointing forward from $A$ to $B$, one back from $B$ to $A$ (Figure 12.1). These are the two faces of relevance: effectiveness and appropriateness. The forward-pointing arrow represents the effectiveness of $A$, that is, the sense in which the sign A gives rise to B as an interpretant or relevant 


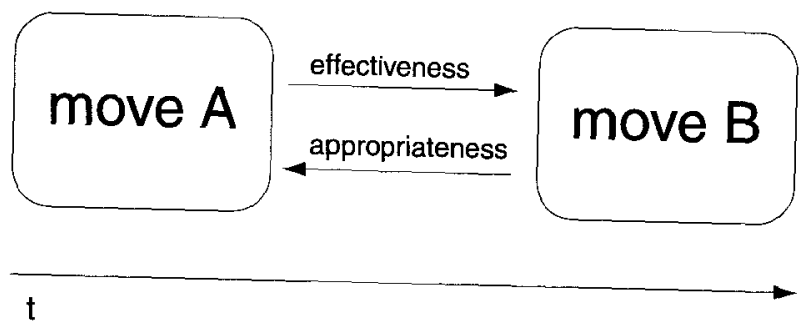

Figure 12.1

response. The backward-pointing arrow represents the appropriateness of $B$, that is, the sense in which B is "fitting" as a next action from $A .{ }^{3}$ Now, the following point is critical to the rest of this chapter's argument: effectiveness and appropriateness are normative notions. Our attention is only drawn to them when there are violations. The more likely B is to elicit surprise or sanction, ${ }^{4}$ the less appropriate it is to A, and the less effective A has been in eliciting a response.

Here is an example from Schegloff (1992: 1310):

(2)

1 ROG: It's always this uhm image of who I am

2 'n what I want people to think I am.

$3 \quad(0.2)$

4 DAN: And somehow it's unrelated to what's going on

5 at the moment?

6 ROG: Yeah. But $t(h)$ ell me is everybody like that or

7

8 KEN: am I just out of [it.

[I- Not to change the subject

${ }^{3}$ There is a second-order sense in which the arrows can go in the other direction. As John Heritage points out (pers. comm.), a responsive move can have an effect upon the prior move by "retrospectively" determining which action the prior move is performing. Note, however, that it does this by exploiting the backward-looking relation of appropriateness: if turn 1 is ambiguous between meanings $X$ and $Y$ (say, an observation versus a complaint e.g., The trash hasn't been taken out), then turn 2, by being an appropriate response to $Y$ but not X, is then able to "determine the meaning" of turn 1 (as long as it is allowed to go through, without correction). Paul Drew points out (pers. comm.) that when people make "pre's" to offers or invitations, this is an opportunity for a response to "make" the pre itself into an offer, and, if this is not forthcoming, we can say it never was one. But this is not the same sense of effectiveness as intended here, that is, the sense in which turn 1 is what causes or occasions or gives rise to turn 2 taking place at all.

${ }^{4}$ I am not speaking of surprise or sanction at the content of what is communicated per se, but at the relation of relevance or appropriateness to what is being responded to. And note also that "what is being responded to" can cover not just prior communicative actions such as a question that precedes an answer, but also other types of signs such as (pre-)existing states of affairs, like the physical structure of a grocer's store and the receptive stance of the shopkeeper that "precede" the possibility of a customer stating what he wants to buy. 
9 but-

10 ROG: Well don't change [the subject. Answer me.

II KEN:

12

13

14

[No I mea- I'm on the subject.

I'm on the subject. But- I- I mean "not to interrupt you but-" uh a lotta times I'm sitting in class, I'll start- uh I could be listening. .

In lines 6 and 7 Roger asks, "But tell me is everybody like that or am I just out of it?". This sets up a strong normative expectation that an answer be provided next, and when this is apparently not forthcoming - i.e., when the norm is violated - in lines 8 and 9, Roger is within his rights to sanction Ken and demand his entitlement to be answered, as seen in line 10. Ken's subsequent response shows that he also acknowledges Roger's entitlement.

Of course, surprise and sanction are measurable in degrees. Suppose John asks Paul Is that a martini you're drinking? If Paul's response is No, this will run against a preference for confirmation (Heritage 1984b), thus departing in one sense from what is preferred or "expected." But at the same time a "No" answer conforms precisely with an "expectation" that the addressee will respond to the question by giving the information that was asked for. A "No" answer may be mildly inapposite, but would not be as readily sanctionable as, say, if the addressee were to ignore the question and remain silent where response had been due; here, Hey I asked you a question would be a justified pursuit of the normative target by way of sanction - see the example just above. The possibility space for degrees and kinds of surprise and sanction is a complex one (Schegloff and Sacks 1973). The normative expression of sanction and surprise helps to regiment and qualify the ever-present properties of appropriateness and effectiveness that are inherent in chains of relevance. The inherently normative nature of an enchronic system means that we cannot begin to examine human communication without entering a realm of morally governed social behavior.

To summarize: enchrony is grounded in relevance, from which we ultimately derive not only sequence (in the enriched sense of Schegloff [1968, $2007 \mathrm{~b}]$ ), but also a bedrock of public, norm-governed accountability for each increment in a communicative sequence. The notions of effectiveness and appropriateness, defined as they are by "expectation" and the surprise or sanction that may result from transgression of this expectation, take social interaction and transform it into a morally charged affair. For all social creatures, a poorly formed or poorly chosen move may be

${ }^{5}$ By using the term "expected," I do not want to imply that a response must be actively anticipated. It is not so much that one expects a particular response, rather that one does not expect the alternatives. 
ineffective, but only among humans can such a mismatch lead to moral sanction. Inappropriate responses draw attention, and are accountable. This accountability is natural given the fundamentally cooperative nature of human social life (Axelrod 1984; Boyd and Richerson 2006). Our instincts for moral policing, including punishment, form an indispensable part of maintaining the viability of a cooperative bias in large social groups (Henrich et al. 2004; Boyd and Richerson 2005). Not surprisingly, these instincts for moral monitoring and sanction are well expressed in communicative practice.

I have described enchrony as a core driving force in the interpretation and production of communicative actions. With it, we derive central structural properties of interaction such as sequence, adjacency, nextness, contiguity and progressivity, well known and described in conversation analysis but barely comprehended in linguistics. We see the lamination of normative reasoning onto this structural trajectory: departures may draw not only surprise at not having been anticipated, but also implicit or explicit sanction for not having been regarded as appropriate. But while enchrony is clearly part of the foundational undercarriage of interaction, it cannot single-handedly account for the phenomena explored in this book. The mechanism of enchrony is a general one. What I have proposed so far does not yet explain how this general mechanism is relativized to different contexts, such that a certain type of response may be appropriate in one situation but not in another. Clearly, what counts as appropriate and effective must be defined relative to elements of the situation, including facts about the people involved in the interaction, as well as the different cultural settings in which interactions take place. To address this, we now build on the idea of enchrony by using it to develop a notion of status.

\section{Status}

The second piece of the argument hinges on the concept of status. The word "status" is used here in a technical sense, derived from Linton (1936), and fleshed out in recent work by Kockelman (2006b). It will never be used in this chapter to mean prestige or "high status." Status here is akin to the notion of membership category used in ethnomethodology and conversation analysis (Sacks 1972a, b, 1992; cf. Schegloff 2007b) ${ }^{6}$ A person's status is defined here as a collection of his entitlements (or rights) and responsibilities (or duties) at a given moment, relative to other members of

- This notion of status does not imply that a social category is immutable or in some other sense not contestable or negotiable. 
his social group. We can characterize these entitlements and responsibilities in terms of enchrony and its elements, as introduced in the previous section, without introducing new analytical machinery. The concepts of entitlement and responsibility are defined straightforwardly through the relations of appropriateness and effectiveness that hold for any communicative actions in enchronic sequence. A person's status is functionally no different from a sign that precedes or co-occurs with a piece of their behavior, ${ }^{7}$ where the fit between the status and the behavior can be assessed for its relevance. The behavior will have a degree of appropriateness or effectiveness, as measured for instance by the degree of normatively justified surprise or sanction in response.

If John is a university lecturer, we can say that this is a status because it may be characterized as a set of entitlements and responsibilities regarding his social relations with certain other people in certain communicative contexts. While inhabiting or enacting this status, he will have rights and duties in relation to his behavior toward his students. Were he to invite one such student out for cocktails, this might attract surprise and possible sanction, while the same invitation among the same two people would be unremarkable if the lecturer-student relation did not apply. As long as his status as a lecturer is in the common ground of an interaction (and is "activated" in the relevant sense, i.e., that he is relating as a lecturer to his interlocutor), the relation of relevance that holds between his status and a piece of his behavior is functionally the same as a relation between two signs or communicative actions in sequence. The appropriateness of his behavior is judged in terms of its fit or relevance given his status. Correspondingly, the effectiveness of his status is measured in terms of its fit to the behavior he produces (see Garfinkel [1967: ch. 4] for a rich exploration of this issue with reference to gender).

As Linton put it, status is polar or relational, thus not to be understood in terms of intrinsic properties ascribable to a person as an individual, but defined in terms of how that person behaves in relation to others. So, to say that Mary inhabits the status of mother is not to say something about the isolated qualities of Mary. It is to say that she behaves and responds in ways that are appropriate to being in the relation of mother to someone (her children). Status is a set of publicly norm-guided expectations as to how a person will or should behave.

7 This is where we need the notion of "sign" as a higher-level category which subsumes communicative actions, among other things. My status is signified in various ways - for example, by the clothes I am wearing - but we do not want to say that by merely putting on these clothes I am performing a communicative action in the normal sense of that term (i.e., a move in a sequence of interaction). 
Ryle (1949: 45) described status as an "assemblage of performances," a set of possible actions, or dispositions, that, when filtered through relevance and norms, become entitlements and responsibilities. ${ }^{8}$

A drunkard at the chessboard makes the one move which upsets his opponent's plan of campaign. The spectators are satisfied that this was not due to cleverness but to luck, if they are satisfied that most of his moves made in this state break the rules of chess, or have no tactical connexion with the position of the game, that he would not be likely to repeat this move if the tactical situation were to recur, that he would not applaud such a move made by another player in a similar situation, that he could not explain why he had done it or even describe the threat under which his King had been. (Ryle 1949: 45)

Our entitlements (what we may do) and responsibilities (what we must do) are captured under Ryle's general notion of dispositions. I suggest that there is a third category of dispositions that may be termed enablements, that is, things one can do. If entitlements are what we are allowed to do (e.g., a mother will typically be allowed more immediate access to her child's body than other adults), enablements are what we are capable of doing (e.g., a mother will typically be capable of predicting the preferences and reactions of her own child better than others can). The measure of entitlement is the degree to which surprise or sanction at carrying out the action is normatively justified. The measure of enablement is the degree to which one is capable of carrying it out at all, regardless of how it will be treated by social others.

Through entitlement and enablement we can articulate a fundamental distinction between claiming and demonstrating. (See Heritage [2007: 255] and his discussion of Sacks 1992: II, 141.) If I want to claim that I am a marksman I can use mere words to do it, or even words supported by a lucky shot. But to demonstrate that I am a marksman I have to produce an assemblage of performances that would not be possible were the claim not true. To the extent that inhabiting a status can be determined by isolated definitive facts (e.g., Mary is John's mother because she gave birth to him), it may constitute a mere claim to the total assemblage of performances that may come under the relevant culturally developed notion of the status "mother to." Thus, we might cite Mary's inability to produce this broader range of performances (e.g., failure to accurately predict the behavior of her child, when a nanny has more success in doing so) as evidence that she is a poor example of a mother (in one sense). This would be a case of mismatch between enablements and entitlements. It is a gap between the claim derived from her "official" authority (she gave birth to him so this makes

8 The point was amply elaborated some twenty years later in the work of Sacks (1972a. b) on

"membership categorization devices" (Schegloff 2007b). 
her his mother) and the demonstration enabled by her "actual" authority. (Below, I will define "official" and "actual" authority as status-based and source-based, respectively.) This is a difference between the two forms of status that Linton called ascribed (mother, brother, etc.) versus achieved (friend, enemy, etc.).

It appears that in the business of maintaining statuses - a desperate pursuit that dominates our social lives - it is not enough merely to possess enablements and entitlements. One must exercise these as a way of demonstrating that one has them (and has earned them), both by proving with action that one is capable of carrying them out (not possible in the case of the "bad" mother who cannot reliably predict her child's behavior) and by showing that, having carried them out, no sanction by another is justified (e.g., by disciplining the child for misbehaving, knowing that she cannot rightfully be criticized by others for doing so).

For example, if we are to say that Mary and Jane are close friends, then they have certain entitlements and responsibilities in relation to one another. Their behavior with regard to one another may be judged as more or less effective of, or appropriate to, their status as close friends. Thus, if Jane talks to Mary about her personal troubles, this should cause no surprise and would not be justifiably sanctioned (in contrast, say, to when Jane starts telling her personal troubles to a stranger on the subway). Or if Jane asks Mary for a loan of $\$ 100$, this is likely to be effective, and would not be inappropriate for close friends. It may, however, be both ineffective and sanctionable in the context of more distant kinds of personal relationship. If Jane and Mary are already (known to be) close friends, then behaviors of the kind just described will be judged as appropriate, and will not justifiably elicit surprise. But, supposing they were not close friends, to behave as if they were could be effective of (or constitutive of) that status, i.e., could be a way of creating that status. ${ }^{9}$

Status is a powerful notion because it defines human relations at many levels of grain and in many types of frame. Statuses run from professional relations like doctor to patient or experimenter to experimental subject, to kin relations like older brother to younger brother or grandmother to grandson, to interpersonally achieved relations like best friend to best friend or acquaintance to acquaintance, and finally to context- or experience-defined relations like expert to novice or competitor to competitor. It includes the broadest imaginable range of human types, including ad hoc categories (such as "people you can turn to" [Sacks 1992]).

9. See Pomerantz and Mandelbaum (2005) for a review of practices through which people can "enact incumbency" in types of close social relations. 
Of special interest in the rest of this chapter, and in much of this book, is interactants' status relative to each other as complementary participants in roles like speaker (to hearer), or overhearer (to others in a conversation). Recall the example above where we saw that Ken's not answering a question was an accountable failure. That kind of accountability was described in terms of the elements of enchrony: effectiveness and appropriateness. Having introduced the notion of status, we now see that this accountability is relativized. It matters who answers the question. If I address you, then it is you who should respond, because it is you who occupies the status of "addressee of the question" (Stivers and Robinson 2006). While another person may well know the answer and be able to respond, possibly on your behalf, this other person does not occupy the same status as recipient of the question. Here we see the relevance relation being relativized to different participants through differences in status. This is illustrated in the following example from Stivers and Rossano (2010):

Reina asks Tamaryn whether her boyfriend's mother calls to talk to her on the phone [line 1]. Tamaryn fails to answer the question in the course of the following 1.0 second [line 2], but at that point co-present Sandra quips "No that (d) ('ll) be wastin' minutes." (line 3 ).

(3) (Stivers and Rossano 2010) [( $(\mathrm{R}$ gazing in T's direction; $\mathrm{T}$ off camera $))$

I REI: $\rightarrow$ [Does she call you and conversate wit'=ju on your phone?.

$2 \quad(1.0)$

3 SAN: No that ('d)/('ll) be wastin' minutes.

$4 \quad(0.5)$

5 SAN: [Th-

6 REI: $\Rightarrow$ | Ta- I want Tamaryn tuh answer the damn question. $<$ Don't

7 |answer for (h) |her

8 SAN: [O(kay) [I'm sorry.

9 REI: ((leaning towards Sandra)) Oh no it's okay.

10 TAM: She called once to see if my mother had thrown a fit but no: other than that_

Although Sandra's response is formally type matched (Schegloff and Sacks 1973 ) and type-conforming (Raymond 2003) it is nonetheless treated as failing. Reina both indirectly sanctions Tamaryn for not answering (indirect only in that the turn is nominally addressed to Sandra): " $>$ Ta- I want Tamaryn tuh answer the damn question. $<$ " and directly sanctions Sandra for answering on Tamaryn's behalf: "Don't answer for her" (lines 6-7). This sanctioning elicits an apology from Sandra and, ultimately, an answer from Tamaryn (lines 10-11).

Status casts our behavior in the constant light of a measure of appropriateness or fit: knowing this person's current status (that is, the status that is presently activated), how appropriate is her behavior? Or: seeing her 
current behavior, presuming (as, by default, I will) that it is appropriate behavior, what does this tell me of her status? ${ }^{10}$ As Sacks (1992) notes, any instance of "category-bound activity" contributes to our further understanding of, and expectations of, the relevant social statuses.

In this section, I have introduced status as an analytic notion that puts meat on the bones of enchrony. Status provides a mechanism for giving values to the variables of appropriateness and effectiveness, and relativizing these across different types of social relation and cultural setting. Both enchrony and status are sources of asymmetry in communication. From enchrony, there is asymmetry in precedence relations and in the associated one-way notion of response. From status, there is an unequalness of social relations, readily seen in relationships like father-son, shopkeeper-customer or speaker-hearer. There now remains a third source of asymmetry in communication that will account for a further crucial aspect of the problem explored in this book - the distributed nature of responsibility and commitment concerning knowledge and information in communication. We turn now to the issue of knowledge, in relation to the semantic and pragmatic content of propositions. This will require the concept of status, already introduced, and must be fleshed out before we move on to the final piece of the argument, agency.

\section{Propositions and the relativity of knowledge}

Human communication, through language, differs from other forms of animal communication in that it can involve the encoding and exchange of propositions. While the informational properties of propositions are not typically a matter of discussion in research on the structures of conversation, they are presupposed. The step into research on matters surrounding knowledge and certainty requires us to have an account of just what it is that propositions encode. We therefore need to address propositional content if we are to have a theory of how asymmetries in knowledge are navigated in social interaction.

In order to pursue our primary interest here - the meanings of social actions in interaction - it is necessary to examine the properties of one of the most common elements of action formulation: the linguistically encoded

${ }^{10}$ We can tell whether two people are friends or strangers from their behavior toward each other; such inferences from social behavior are the basis of Hinde's (1976) account of how the ethnographer ultimately discerns higher-level social structure; see also Dunbar (1988), Enfield (2006). An illustrative case is that of Princess Margaret, who, in a fleeting moment at Queen Elizabeth's coronation in June 1953, revealed the intimacy of her relationship to Group Captain Peter Townsend by leaning over to brush a piece of fluff from his uniform. Through what it showed about the social relation at hand, this little act had big consequences. 
proposition (see Lyons 1977). A proposition refers to some entity, and predicates some state of affairs (e.g., a property or event) about that entity. An example is the proposition "She called once", encoded in the utterance produced by Tamaryn in line 10 of the above example. In this proposition, the entity is "she" (referring to the speaker's boyfriend's mother) and the state of affairs is "to have called once." If we know who "she" is and we understand the meaning of the expression "to have called once," then we are in a position to judge the applicability (say, truth or falsity) of the predication to a particular instance. If we understand the meaning of the proposition, then we are able to cite possible reasons the state of affairs holds, and we are able to make inferences from this state of affairs to other propositions. This is, of course, not an account of utterance meaning or action formulation, but it is a necessary part of such an account.

This introduces a triadic relation between a topical entity, a predicated state of affairs, and a person who may judge the applicability of the relation between the first two. We may refer to a person's capacity to make this judgement - measurable by their capacity to attest to the truth of, to give reasons for, and to make inferences from the proposition as understood - as their knowledge. We can imagine a gradient of possible states of knowledge between knowing for sure (e.g., I know she called once because I took the call myself) and having no idea. Perhaps I overheard Tamaryn on the phone to somebody who I figured was the boyfriend's mother, but couldn't be sure.

A knowledge state is like a status in that it is causally-conditionally related to its causes and effects, and is measured by the behavior that it makes possible. As argued by ordinary language philosophers like Ryle (1949). it is not so much an issue of my mental state of knowing something to be true. What matters is how I can demonstrate this knowledge through observable action, specifically by giving reasons (my evidence for the truth of the state of affairs, what caused the knowledge, the source of the knowledge) and by making inferences to consequences (what the knowledge enables, what performances are made possible by the state of affairs). I am proposing that knowledge of the truth of a proposition is no different from other status-related dispositions, displayed and demonstrated through an assemblage of performances, like any other kind of status. This is in line with an "inferentialist" view of meaning (Brandom 1994, 2000; Kockelman 2005. $2006 \mathrm{a}, \mathrm{b})$, which states that to know the meaning of a proposition is to be able to engage in norm-governed practices of reasoning in relation to that proposition. Such reasoning is simply an assemblage of performances that demonstrates some aspect of one's status - in this case, one's proper understanding of the sentence's meaning, of its veracity and applicability in relation to a particular state of affairs. We have to presuppose that, in 
the context of Tamaryn's utterance in line 10 of the example above, the participants can and do draw on a capacity to judge the veracity of propositions like "She called once".

What is the relevance of all of this to social interaction? Well, among our most common tools for the formulation of social actions are propositions encoded in language, and it is here that we find ourselves navigating the rocky shoals of asymmetries in knowledge. If I know something, then I can or must commit to the consequences of that knowledge. Consequences include inferences that can or must be made. If I know about something, then I can say things about it. ${ }^{11}$ This is how one demonstrates understanding rather than merely claiming it, as shown by line 3 of the following example, constructed by Sacks (1992) and discussed by Heritage (2007):

(4)

1 A: Where are you staying?

2 B: Pacific Palisades

3 A: Oh at the west side of town

Here, Speaker A demonstrates that among his enablements is the ability to correctly deploy a proposition about Pacific Palisades to state that it is found on the west side of the city of Los Angeles. This attests to his knowledge. The key about demonstrating is that it is an honest signal, while mere claiming is not. As Sacks points out, were the speaker to reply in line 3 "Oh, Pacific Palisades", no demonstration of understanding will have been made. One could say it even when one has no idea where Pacific Palisades is. Here is an example in which a speaker merely claims rather than definitively demonstrates their understanding (from Sacks 1992: II, 141):

(5)

1 A: Now you told me you eh-uh-where are you.=Are you at uh:Puh-ih: (.) Palos uh:(0.4)

2 B: eh-No in ah:::::uh: (·)t Marina del Rey.

(0.9)

3 B: Marina del Rey.=

4 A: =Oh Marina del Re: ly.

5 B:

[Yah.

Cases like this are apparently common, while curiously, as Heritage (2007) notes, real demonstrations of understanding of the kind shown in the made-up Pacific Palisades example are rare (hence the need to fabricate them). Why do people avoid demonstrating their understanding in favor

"I focus here on the creative vector of indexicality (Silverstein 1976), where knowledge of the matter creates the possibility of expounding on it. Conversely, we could focus on a presupposing vector, where my expounding on it is a way of indicating (or perhaps merely claiming) my earlier learning experience(s). 
of the weaker stance of merely claiming it? There are at least two reasons. First, as John Heritage points out (pers. comm.), a full demonstration of one's understanding goes against a preference for progressivity (Stivers and Robinson 2006), in that it is likely to open up a new sequence, however minimal, thereby risking delaying or completely derailing the trajectory of talk. To avoid this, a recipient might imply understanding with a continuer like "uh-huh", and in this way give the go-ahead without disrupting the speaker's current trajectory. But note how in the Marina del Rey example, the speaker does in fact risk a disruption to progressivity (here eliciting from the speaker a further confirmation "Yah"), yet still without using that opportunity to definitively display recognition. It could still be that Speaker A in the example doesn't recognize the name of the place or doesn't know where it is. This points to a second reason why a mere claim to understanding may be preferable to a full demonstration. To positively demonstrate my understanding by going beyond what was said earlier is at risk of being disaffiliative because it draws attention to the possibility that I didn't in fact know it (i.e., why did I need to demonstrate it?). and through this to the possibility that you might have thought I didn't know it. Showing that I don't feel the need to "prove" that I know something is a sign that I expect to be trusted by the other, or indeed that the other knows what I know (Enfield 2006), and is thereby in itself an expression of trust. Going out of my way to prove that $I$ know it risks drawing attention to these asymmetries, something that can quickly get an interactional trajectory wobbling into turbulence.

While Pacific Palisades examples appear to be rare, they do exist. In the following case from a telephone call (Heritage 2007: 271; transcription simplified here), Marsha has initially not recognized the voice of Ron, an old friend of her daughter. (This occurs prior to the segment supplied below.) When Ron announces his name in line 1, Marsha makes a strong claim to recognition in line 2 , but it is no more than a claim, particularly in the context of her initial failure.

(6)

1 RON: This is Ron Mercahno do you remember me?

2 MAR: Oh for heaven sake Ron Yeah this is Marsha

3 RON: Marsha right

What comes next is the less frequently observed demonstration of recognition, in line 4 :
4 MAR: You're writing for television
5 RON: Yeah
6 MAR: The writing for television Ron
7 RON: Yeah 
So far we have examined how knowledge is displayed through either claim or demonstration. Now we attend to finer points of distinguishing between (relative) degrees of certainty, and matters of how the knowledge has been obtained. Suppose we both know that Tamaryn got a phone call from her boyfriend's mother, but I was in the room when it happened, while you only heard reports of it later. While we are both equally able to say that she called, there are two reasons why I am better qualified to say it: (1) my knowledge is on firmer ground than yours: because I was present I am more certain than you that it is a fact - that is, I have better evidence than you and so I am more likely to be telling the truth despite the fact that we may both be speaking in good faith; and (2) because I directly witnessed the event I can say more things about it, such as how long the call went on for, how Tamaryn responded and so on. We thus distinguish two components of our knowledge of a proposition: access, that is, our source of information and thus our citable reasons for being committed to the truth of it; and authority, our capacity to demonstrate the effects of knowing that information, through the dispositions enabled by whatever access we have had. (Access leads to the knowledge; authority leads from it.)

It is evidently a matter of concern to people that their degree of knowledge, and grounds for knowledge, be made public by means of various kinds of marking, implicit and explicit. If I am less certain of the truth of a proposition (or wish to claim this for some communicative purpose), I may feel the need to hedge, as in "I think she called once" or "Maybe she called once." I may make explicit reference to my source of evidence, as in "I heard that she called once," as is grammatically coded in many languages by systems of evidentiality that obligatorily mark whether I perceived something myself, whether I have it on hearsay alone, etc. (Aikhenvald 2004). Such marking appears to be primarily or literally concerned with first-order absolute knowledge, that is, the relation between the speaker and the content of the proposition.

Based on the preceding discussion, it is useful to introduce a terminological distinction here, between source-based authority and status-based authority.

Source-based authority concerns actual experience and what it enables. If I was present when Tamaryn took the call from her boyfriend's mother, then I can cite this direct experience in support of my commitment to knowing it. This notion of access is a backward-looking basis for commitment, pointing back to what gave rise to the knowledge. The authority in question concerns that which the knowledge makes possible: namely, the range of things I can say or do as a result of that knowledge. 
By contrast, status-based authority concerns not what you actually know, but what you should know, or are entitled to know, given your status (Drew 1991: 37ff.). Source-based authority and status-based authority are typically in alignment, but sometimes they are not, as in the case of the mother who spends less time with her children than the nanny does (cf. Raymond and Heritage 2006). Concerning the matter of knowledge of the children's personality traits, the nanny has higher source-based authority than the mother, while the mother has higher status-based authority. Were we to measure authority by means of the capacity to cite experience (what gave rise to the relevant knowledge) or the capacity to reason and make predictions about the children's behavior (what is enabled by the relevant knowledge), the nanny would win. But by a different mechanism, as part of the mother's ascribed status as mother, among her normatively defensible entitlements are that she may claim maximal epistemic access regarding her children (and therefore higher, or at least not lower, access than anyone else). Note that this is not just so by fiat. but is based on the genuine expectation that she will have maximally broad experience with the children, as a proper result of having fulfilled her responsibility (as also defined by her status as mother) to spend maximal time with the children. The nanny example deals precisely with this mismatch. When the nanny demonstrates better authority of the mother's children than does the mother herself, this reveals that the mother displays diminished (less than maximal) source-based knowledge with regard to her own children. The core of the problem is that this demonstrates that the mother has not fully lived up to her responsibilities as given by her ascribed status as mother. It draws attention to her shortcomings as a mother, and, in effect, draws her status as mother into moral question. It is no wonder such misalignments are fraught.

Heritage and Raymond (2005) explore the difficulties that arise when two speakers pursue a symmetrical goal of agreement on the applicability of a proposition to a known state of affairs, but where these speakers find themselves having to navigate the asymmetries introduced by status and enchrony. Their illustrative case is from a conversation between two friends, Jenny and Vera, who agree that Vera's grandchildren make up a lovely family (2005: 20). Heritage and Raymond introduce a notation for representing knowledge or epistemic commitment. In their shorthand, " $K+$ " with reference to Speaker $A$ is not absolute but relative, meaning " $K+$ for $\mathrm{A}$ and $\mathrm{K}-$ for B." This introduces four extreme possibilities (though Heritage and Raymond only specify two) where both A and B may have a value of either K-low or K-high. When both A and B are low, or when both are high, these appear to be symmetrical situations (though I argue in 
the following section that this can never really be so, due to inherent asymmetries of speech act agency). Possibilities other than the two identified by Heritage and Raymond are conceivable: A's knowledge is more than B's (" $\mathrm{K}+$ " in relative terms), but still it's quite low (i.e., approaching " $\mathrm{K}-$ " in absolute terms). We can imagine that in some situations it is important to mark one's degree or kind of absolute knowledge, while in other situations it is the relative knowledge that matters. The distinction needs to be made and maintained (see Hayano this volume).

I noted above that knowledge can be explicitly marked. But it is also implicitly marked. Commonly, a proposition coded as a bare assertion (e.g., "She called once") will be taken to convey the strongest possible epistemic commitment, namely "I know for a fact it is true" (Grice 1989). In a bare assertion in English, this maximal epistemic commitment is implied rather than coded. To code this one would need to make it explicit, as in I know that she called once. This sounds overwrought, and defensive, as if it had been suggested that you didn't know whether it was the case. But everyday statements are backed by the everyday assumption that a speaker has adequate evidence for what she is saying (Grice 1989; Pomerantz 1984b). If anything less than full commitment is intended, this should be explicitly marked. As mentioned in Sidnell's chapter on English (in this volume), when we preface a proposition with I think, this implies "I don't know it," or - perhaps better - "I don't want to say that I know it."

Note in addition the way that relative knowledge is also implied in fundamental ways through the presuppositions that are inherent in speech act types (Searle 1969). Declarative forms - as in She called once - imply not just "I know it," but also "You don't." This is one reason that "assessments" (Goodwin and Goodwin 1987; Pomerantz 1984a) - as in Adeline's such a swell gal - are problematic in epistemic terms: their packaging is fitted to a strong asymmetry in knowledge (i.e., in declarative format, they are ostensibly "telling" the addressee something), yet their function is often aimed at full symmetry, i.e., securing agreement (Heritage and Raymond 2005).

In this section I have concentrated on a particular mode of status within the domain of epistemic commitment to the content of propositions. As we have seen, the fact that using language includes the encoding of propositions raises a rich set of issues for social interaction. First, there is the matter of access: our source of knowledge, the evidence we have for it, how we acquired it. Second, relatedly, there is the matter of authority: the enablements this access to knowledge brings, such as the capacity to demonstrate our knowledge through reasoning (a capacity of the same kind Ryle offered as evidence for mastery in chess or marksmanship). An indi- 
vidual's knowledge is grounded in access, and is measured by authority. But there is another, parallel basis for a claim to epistemic commitment, namely one's normative rights to certain kinds of knowledge, based on status. If I hold the title of chess champion of South Gelderland, I may have some claim to speak with authority about chess, even if I am not all that good a player and was merely lucky to have won (or cheated). And you may even find yourself biting your tongue out of deference to this claim, even when you are certain that what I say about chess is dubious (just as a nanny may find herself doing when a mother is wrong about her own children, or as a student may find herself doing when a lecturer is wrong about his topic). Thus we distinguish between source-based and status-based authority. We then saw that these nearly parallel modes of commitment to knowledge are further relativized across participants in an interaction: one person may always be regarded as higher or lower than another, based on source-based authority, or a status-related claim to such authority. It appears that a status-based claim trumps a source-based demonstration when the two are in conflict. This is a paradoxical fact, if true, but perhaps not unexpected given that we are not so much rational as moral animals.

\section{Agency}

Our account began by grounding human communicative practice in enchrony - a generic mechanism that yields sequence, relevance and accountability - then relativizing this through the notion of status to culturally determined and locally contextual types of social relation, and finally focusing on the nature of knowledge as a species of status relating to states of affairs and the things we can say about them. The previous section introduced some ways in which speakers and hearers stand in relation to knowledge of propositions and responsibility for the formal expressive (e.g., grammatical) packaging of that knowledge, and how this interacts with respective status beyond speech act participation and into social-cultural categories. We must now introduce a fourth piece of conceptual apparatus in order to fully account for the matters of knowledge, responsibility and affiliation explored in this book. Status alone is not sufficient to account for some of the empirical data that previous work has introduced. We are missing a final source of asymmetry that interacts with enchrony, status and knowledge - namely, agency.

The term "agency" has been so widely applied that it may be wise not to use it at all. Mostly in this chapter I am referring to the elements of "speakerhood" by which a person may have more or less control over various 
dimensions of an utterance (Goffman 1981). However, I cannot use the term "speakerhood" here because I want to generalize beyond speech. I am trying to capture the type and degree of control and responsibility a person may have with respect to their design of communicative actions and other kinds of signs.

There is no scale by which we may say that a person's agency in communication is simply higher or lower. Instead, agency has multiple distinct components that may be addressed separately. Agency may be distributed across individuals. This introduces an ever-present potential source of asymmetry, logically distinct from the asymmetries inherent to enchrony and status. The compound notion of agency assumed here is akin to Goffman's disassembly of the agent of any speech act into three: animator, author and principal.

Roughly, the three elements of agency can be characterized as follows. ${ }^{12}$ First, with respect to any behavior, such as the production of a perceptible sign, somebody will control the behavior to a greater or lesser extent. That is, they control the physical execution of the sign such that it can be perceived and attended to by another. Second, somebody will compose the behavior, selecting and planning what its form should be so as to bring about the projected effect. Third, somebody will commit to the behavior, taking responsibility for its causes and effects, including the appropriateness of its execution in a specific context. In Goffman's terms, who controls the production of the message is its animator; who composes the form of the message is its author; and who is responsible for the effects of the message is its principal (though see Kockelman [2007: 379, fn. 5] for problems with Goffman's "principal").

Goffman made the point that, while the three components of agency in speaking tend to be aligned, they are in fact separable, as shown by examples like the police spokesman who reads a prewritten message (animator, but neither author nor principal), or the head of state who delivers a policy speech scribed by an advisor (animator and principal, but not author). But, normally, each of the three elements of agency in speakerhood is embodied in one and the same person. If a man remarks to his wife, "That dress really suits you," she will know through direct perception that he is the animator of this utterance, and she should normally assume that he composed the specific expression of it, and that he takes responsibility for what it expresses and for the effects it may have. When a listener applies this

12 The present account draws on Kockelman's (2007) account of agency, which is directly grounded in a more general semiotic theory, after Peirce. I leave aside here the complexities of possible finer interpretations of the Goffmanian scheme (Hanks 1996; Irvine 1996; Levinson 1988; Sidnell 2009). 
ordinary presumption of alignment of the three dimensions of agency, she is applying an agent unity heuristic. ${ }^{13}$

Note the inherent difference in access that we have to the three components of agency. We typically have direct access to animatorship, because we have to be present to perceive the production of an utterance. But we don't typically have direct access to the process of authorship (usually carried out privately, that is, mentally), ${ }^{14}$ nor necessarily to the conditions of responsibility and commitment that define a principal (though these are sometimes publicly available through standard signs of status: e.g., accent, clothing, physical features). It is because of the agent unity heuristic that we need special devices to mark when agency is distributed. This heuristic is a powerful one, and if we want a hearer to suspend her standard application of it, formal means are required to signal this. These include signals of quoted speech, contextualization cues, etc.

To illustrate why agency, and in particular the agent unity heuristic, is necessary in the present account, consider the study by Heritage and Raymond (2005:34). The authors present data from conversation in English in support of the argument that "assessing a referent state of affairs in first position implies a claim of primary epistemic and/or moral rights to assess that state." Here is how they summarize their findings.

In sequences of interaction, first position assessments establish a representational field in which second assessments will be found to position themselves in some fashion: through agreement, disagreement, or adjustment (Heritage 2002a; Pomerantz 1984a). In this sense, first position assessments offer a terrain within which agreement will be sought. We propose that these assessments also carry an implied claim that the speaker has primary rights to evaluate the matter assessed. For example, as we demonstrate, persons offering first assessments may work to defeat any implication that they are claiming primary rights to evaluate the matter at hand. Conversely, persons who find themselves producing a responsive assessment may wish to defeat the implication that their rights in the matter are secondary to those of a first speaker. Because assessments are always produced in real time and are unavoidably produced as first and second positioned actions, they bring unavoidable relevance to issues concerning relative epistemic rights to evaluate states of affairs. (Heritage and Raymond 2005: 16)

13 "Heuristic" here refers to an interpretive strategy that applies a simple rule of thumb in order to simplify what might otherwise be a complex decision-making process (Gigerenzer 2007). For example. in selecting which brand of soap powder to buy. I simply buy the same one I've used before, rather than testing out every new brand that comes along to determine whether it's better or worse on some measure.

14 The psychological process of utterance production can be partially made public through visible indices such as hand gestures (Beattie 2003: McNeill 1985, 2005: cf. Enfield 2009. and references therein). 
The account is grounded in the observation that first position implies primary rights. Why might this be so? First, as Heritage and Raymond make clear, enchrony is what underlies the inevitability of actions being taken as "first" (or initiating) versus "second" (or responsive). But why should first position hereby imply primary rights? I want to argue that there are three mechanisms, derived from the analytical tools brought together here: (1) being the one to say it; (2) saying it in the form of an assertion; and (3) saying it independently. (Note that these are matters of control, composition, and commitment, respectively.) Let us consider these in turn.

How does an agent unity heuristic contribute to the effects described by Heritage and Raymond? I want to argue the following. When you hear and see me speak, it is directly apparent that I, and only I, am animator of the message. Applying the agent unity heuristic, that is, using the most accessible component of agenthood - control or animatorship - to infer the least accessible - commitment or principalhood - the normal assumption will be that if I and only I am animator of the message, then I am also author and principal of the message. This is an animator bias. ${ }^{15}$ The issue here is that animating is typically strongly asymmetrical: the tendency is for one person to speak at a time (Sacks, Schegloff and Jefferson 1974; Stivers et al. 2009), certain classes of departure notwithstanding (e.g., Lerner 2002). Via the agent unity heuristic this asymmetry is automatically imported to the domain of commitment or principalhood. But in the kinds of interactional contexts in which interlocutors strive to build affiliation through the overt expression of agreement, the goal is symmetry of commitment.

In terms of the basic social motives for communication discussed by Tomasello (2008), the problem here is that a structure designed for informing is being used for the function of sharing. This may be a kind of exaptation, a panda's thumb of language use. Along lines argued by Marcus (2008; cf. Jackendoff 1997: 20), the system has the klunky quality typical of evolved systems that must constantly come up with ad hoc solutions engineered out of structures which are available but which may have initially evolved for other functions. One of Marcus's examples is the human spine, evolved to maintain a horizontal position from which the body weight hangs down (cf. other mammals), but which now has to hold our weight vertically, something for which it is not well designed at all. There is an ill fit between the source structure and its target function. Similarly, part of the problem documented by Heritage and Raymond is an ill fit between the asymmetry of animatorship in speaking and the intended symmetry of principalhood in agreeing. But there is more.

15 Shooting the messenger is a kind of collateral damage owed to the agent unity heuristic - i.e., where the one who is merely animator pays the consequences of being treated as principal. 
As noted already, the speech act of assertion itself carries with it the presupposition of an epistemic gradient in which "I know it, you don't." When we make assessments like "They're a lovely family," we are often saying this not to inform someone: rather we are seeking their agreement (Heritage and Raymond 2005: 20). Languages provide us with devices for explicitly marking that this is what we are doing, such as English tag-type strategies ("aren't they?," "don't you think?"), or Lao sentence-final particletype strategies (nòq1 "agreement-seeking polar question marker" [Enfield 2007: 48-50]). But even with such marking, the speaker who goes first is nevertheless somehow "implying a claim of primary rights to evaluate the matter." And there is yet more.

I have so far proposed that primary rights of the kind described by Heritage and Raymond may be implied by (1) being the one to say it (via an agent unity heuristic and an animator bias; if the addressee is "not saying it" then an implication is that they are also not - yet - committed to it); and (2) saying it in the form of an assertion (via the presuppositions of that speech act, namely that the addressee is unknowing). Now we want to know why "saying it first" also conspires to imply primary rights to what is said. As Heritage and Raymond show, the problem is not solved simply by the addressee saying it too, in second position. Thanks to enchrony, an asymmetry still applies. To see why, we need a distinction between speech event and narrated event, introduced by Jakobson (1971) for dealing with matters of deixis.

The speech event is the actual situation of speaking, in which the participants find themselves. It is the proximal realm of reference for words like "I," "here" and "now." The narrated event (or, more accurately, the narrated state of affairs, since it is not always an event) is the state of affairs being talked about. So, if Tamaryn says to Reina She called once, the narrated event is the phone call, and the speech event is the conversation between Tamaryn and Reina (and Sandra). ${ }^{16}$ Note that the speech event is the true realm of enchrony, where relations between communicative actions show effectiveness and appropriateness, regulated by the status of speech act participants. And with regard to knowledge, absolute knowledge is calculated with reference to the narrated event (how sure one is that "She called once"), while relative knowledge is calculated with reference to the speech event, in addition (how much more sure one is than someone else that "she called once").

16 Sometimes, of course, the speech event is the narrated event, or there may be a speech event within the narrated event (in which case words like "I" may have transformed reference, as in John said "I quit," where "I" no longer refers to the actual animator of the utterance). 
Now, if I make an assertion like They're a lovely family, not only do I display a certain epistemic commitment to the proposition in the narrated event ("I know it"), but also I display a commitment to the appropriateness and effectiveness of expressing this proposition as an utterance that contributes to this speech event here and now. In this way I may be held accountable for not one thing but two: (1) that I am committed to the content of what I say; and (2) that I am committed to the appropriateness of saying it here and now. Through this, a "first position assessment" implies a unilateral or independent claim of relevance: not only do I know that they're a lovely family and therefore have authority to say it, but it was my idea to say it in this context (implying: not yours). This is the key problem with going second. There is a heavy asymmetry in agency in the speech event concerning the "cause" of my saying it now - i.e., what engendered or occasioned my saying it now. In first position, what causes me to say it is that "I wanted to say this, now" (I considered it appropriate), but when I respond by agreeing with what you just said, I am vulnerable to losing all perceived agency in the domain of the speech event: i.e., "I'm only saying this, now, because you just said it."

So there are two problems. One is that, by stating it in first position, I invite an implication of priority through an agent unity heuristic and an animator bias ([a] that I'm animating it implies that I'm committed to it; and [b] that only I am animating it implies that only I am committed to it), combined with the inherent pragmatics of formally asserting it ("I know it, you don't"). The second problem is that, by stating it in second position, you risk being perceived to have uttered it only because the other just did. (Or, perhaps better: if you say it in second position, it is possible that you would not have otherwise said it; if you say it in first position, well, you did say it.) The kinds of strategies for upgrading in second position that Heritage and Raymond (2005) describe are precisely designed to defeat these implications (cf. Heritage 2002a).

Consider a situation in which a speaker finds himself saying something that may be interpreted as merely occasioned by what the other has just said. In line 1 of the extract below, Jess asks Mike if he's "boxing right now" - that is, if he's currently training for a fight.

(7)

1 JESS: Are you boxing right now?

2

(0.9)

3 MIKE: I'm gonna start tod^ay.

4 (.)

5 JESS: [Oh:.

6 MIKE: [Tonight actually tuh tell ya thuh tru:th,

7

$(0.3)$ 
8 MIKE: Six fiftee:n.

9 (0.7)

10 JESS: At thuh place on Sta:te Street?

11 MIKE: >State Street.<

When Mike responds after nearly a second by saying "I'm gonna start today", it sounds like he might be opportunistically affirming in response to Jess's question. After all, since he's not in training yet, a "no" response is equally fitting. Instead he claims that he is going to start today, but he does not give evidence to demonstrate that this was already his intention. No doubt Mike doesn't want it to sound like his announcement in line 3 is only occasioned by her asking, which is consistent with what he does then go on to say: in lines 6-8 he is increasingly more specific about the time of starting (from "today" to "tonight" to "six fifteen"), as an offer of independent evidence that he was already planning to begin today, and not because she just asked.

\section{Conclusion}

My objective is a general account of how communicative actions are interpreted, as a function of (1) their context in a sequence of communicative actions, (2) the relative status of the interlocutors involved, including (3) differences in source and authority regarding knowledge about states of affairs being referred to (or otherwise relevant) and (4) the distribution of agency and its features. Taken together these are elements of a framework that is general enough to capture phenomena we already need to capture (e.g., sequence organization, deictic reference, pragmatic implicature), but also able to account for the specific concerns of this book: the complexities of knowledge, responsibility and affiliation. Let me summarize the argument.

I Enchrony. Communication involves sequences of communicative actions in social interaction, where relevance drives interpretation at every step. This interpretation is normatively guided insofar as communicative actions may be seen as more or less effective of the responses they elicit, and responses may be seen as more or less appropriate to the actions they respond to. Enchrony introduces two critical elements of an account for moral responsibility in the communication of information: (1) sequential asymmetry and the literal primacy of "going first"; (2) the potential for normative regimentation of relevance relations via appropriateness and effectiveness.

II Status. The normative structure of interactional sequence is relativized to categories of human relation, defined by cultural and activity 
contexts. The notions of appropriateness and effectiveness are thus transformed into normative context- and person-specific entitlements and responsibilities, which may be morally governed. Depending on the status categories a person enacts at a given moment, he will be accountable for his behavior as measured against his associated rights and duties. The relevant categories of status include social roles from mother and brother to police officer and teacher to speaker and hearer: in all cases, there is an "official" sense of what a person should and should not do (or be capable of doing), and an "actual" sense of what they will or will not be capable of doing.

III Knowledge. Because human communication includes the coding of information in the form of propositions, this introduces a range of issues concerning entitlements and responsibilities relating to knowledge encoded in a proposition. A first-order way of analyzing this knowledge concerns an individual's relation to the information. What they know is a direct result of how they know it: that is, their access to the state of affairs. This may be measured by their authority in demonstrating this knowledge. Distinct from this capacity to demonstrate knowledge, based on real access, there is a parallel but distinct claim to authority based on status - e.g., a grandmother should know her own grandchildren very well, even if in fact someone else can demonstrate knowledge of them that is as good or better. At a second order there is the matter of relative knowledge - that is, the relation between the type and degree of knowledge of two speech act participants. All things being equal, a grandmother knows her grandchildren better than her friend does, but not as well as her own daughter does - the children's mother. Some ways in which epistemic commitment is formally marked (e.g., in speech) are concerned with absolute knowledge, others concern relative knowledge, yet others are more general. ${ }^{17}$ Some marking is explicit, some implicit. Generally speaking, given the statuses and degrees and types of commitment that pertain in a situation, speakers should represent them as accurately as possible, because they are at any point liable to be held accountable - which shouldn't be a problem so long as their strategies of coding are aligned with the facts. Turbulence arises when the many sources of asymmetry fail to align.

IV Agency. A final source of asymmetry in communication concerns the distinctness of the three components of agency. There is an animator

17 Though as Kobin Kendrick stresses (pers. comm.), even those "absolute" markers are used relatively in that they are deployed in ways that orient to the epistemic state of the interlocutor. It may be that the distinction made here between absolute and relative can be more accurately characterized as a cline from the most (explicitly) relative to the least (explicitly) relative. 
bias due to animatorship being the most accessible of the three components of agency: thus, if someone is an animator, we assume that they are also author and principal, unless there is evidence otherwise. But animating is inherently more strongly asymmetrical than commitment or principalhood. The whole point of building agreement and affiliation is in a sense to build a "compound principal" consisting of two or more people in relation to a proposition. The fact that conversation is built around taking turns at unilaterally animating seems to be in direct conflict with this goal. Three mechanisms are at play. First, when you are the one to say it, the other person is thereby not the one to say it, and, through an agent unity heuristic, they also are at risk of being implied to be "not committed to it" either. Second, when you say it in the form of an assertion, this implies that the other is unknowing. Third, when you say' it first, you say it independently, with the agency of having spoken unprompted and having seen it as being appropriate in the context, rendering any direct agreement by the other at risk of being taken as mere following. These asymmetries are grounded in enchrony and agency and they become problematic when they are not aligned with the asymmetries of status and knowledge.

Language use is a complex affair, in which propositions with complex forms of coding are expressed and deployed on an undercarriage that shares much with other species - that is, a communicative system whose primary function is to achieve social goals through interaction. Our system is transformed, however, not only by the complexities of language, but by something else that is unique to our species: pro-social cooperative motives and the moral policing that is necessary to keep a cooperative system going. Facts about human interaction of the kind recorded in the above chapters show that everyday interaction is beset with the difficulties of reconciling a large set of informational and social-relational asymmetries in communication. Why should we experience these difficulties? After all, we are well-practiced users of the communicative systems at our disposal. I suspect that we are doing the best we can with an inherently imperfect system. Problems of the kind described above, where properties of the system produce these clashes, are a necessary outcome of the kluge-like nature of the system as an evolved system (Jacob 1977; Marcus 2008). A recent account of the evolutionary origins of human communication proposes a path of development of social motives for communication. going from requesting to helping/informing to sharing (Tomasello 2008). The core of the problem examined in this book is a conflict between the unalike gradients inherent in these three communicative functions - for instance, as discussed above, there is an inherent imbalance in employing 
an assertive grammatical format (ostensibly for informing) in utterances whose core goal appears to be sharing. If our communicative system is a truly evolved one, then these are precisely the kind of kluge-like imperfections we would expect to have to work around. Sources of asymmetry in the very fabric of the system give us no time out from the moral dilemmas of social interaction. 